Keywords: Medical ethics; Ethical decision; Community treatment order; Civil outpatient commitment; Involuntary treatment; Severe mental illness.

\title{
Community treatment orders: Bioethical basis
}

\author{
José Manuel Bertolín Guillén \\ Service of Psychiatry, Arnau de Vilanova \\ Hospital, Health Department Valencia- \\ Arnau de Vilanova-Llíria, Valencian Health \\ Agency, Valencia, Spain (EU) \\ SPAIN
}

\begin{abstract}
Background and Objectives: Numerous opinions and medico-legal controversies have arisen up to the date from community treatment orders in Western countries, but underlying bioethical questions have not been specifically studied. The aim of this work is to contribute to further clarify the bioethical conflicts arising from community treatment orders.

Methods: The bioethical deliberation of the author is principally based on what can be considered the deontologist-principlist dominant paradigm. These principles, as first described by Beauchamp and Childress in 1979, will be applied in this work to the actual situation of involuntary outpatient treatment.

Results: The author's deliberation considers that community treatment orders are consistent first with the deontologist-principlist dominant paradigm of practical reason, respecting its four general categories of basic principles. It also respects the principles of the medical ethics of virtue, subsumed in the personalism of ontological matrix, in the same way as its ethos affects the intrinsic purpose which is the dignity of the person; and with the consequentialist utilitarianism because it seeks the proportionality of the common good. A community treatment order prescription must ultimately be based on a bioethical exercise of responsibility by the clinician, judiciously weighing up the classic principal prima facie duties which must necessarily be translated into a real duty referring to a specific patient and context.

Conclusions: Community treatment orders are seen as a method of therapeutic intervention with a bioethical basis resistant to criticism.
\end{abstract}

Received: 22 March 2010

Revised: 6 December 2010

Accepted: 22 December 2010 


\section{Introduction}

According to the Mental Health Act 2007 (UK) a community treatment order (CTO) is a legal order made by a tribunal or by a magistrate. It sets out the terms under which a person must accept medication and therapy, counselling, management, rehabilitation and other services while living in the community. It is implemented by a mental health facility that has developed an appropriate treatment plan for the individual person.

Psychiatry has a high ethical profile and in it, more than in other branches of medicine, both sciences and humanities converge. In particular, important medical, legal, philosophical and bioethical questions converge around a CTO. It can also be said that a CTO has a triple dimension: scientific, technological and social ${ }^{1}$. To make things even more complex, the severe mental illness (SMI), which a CTO is aimed at, is a biopsychosocial way of falling ill in persons who show negligent or dangerous behaviours in relation to their basic self-care such as their health. The influence of SMI on these behaviours may vary in intensity over time. Moreover, the diagnosis of SMI itself is not free from bioethical problems ${ }^{2}$. A CTO seeks as its ultimate goal to both restore freedom to certain patients with SMI and enable the best possible integration and social interactions, and it is effective in some of these patients ${ }^{3-10}$. Although the international regulation of CTOs is extremely irregular, it is broadly comprised of three different forms: as an alternative to involuntary admission, as a supplement or continuation of an involuntary admission, and as a preventive measure of involuntary admission. All three of them are referred to in this paper.

The use of CTO and other forms of mandatory outpatient treatment has been controversial. The main negative criticisms to CTO centre around the fact that the evidence of efficacy is not conclusive, that it might tend to substitute integral community treatments for SMI, that it could become an exaggerated and generalized measure applied with too broad criteria and to patients who do not need it. Certain groups of patients consider that involuntary treatments should be in hospital and not outpatient. Important questions on CTO are still being discussed ${ }^{11,12}$. Most of them are about bio-juridical aspects but bioethical topics have not been the subject of special study up to the date.

From bioethics, CTOs are mainly discussed from the deontologist-principlist dominant paradigm of practical reason, breaking down the discussion into its four categories of basic principles ${ }^{13}$. Complementing this approach is the more Judeo-Christian Mediterranean-European tradition provided by the medical ethics of virtue ${ }^{14}$. In connection to CTOs, the medical, volitional and justice aspects of this latter ethical perspective are particularly important, which correspond respectively to the virtues of benevolence, respectfulness and justice to the patient and others. Yet, whatever the ethical perspective is, decision-making clinicians, especially psychiatrists, have to face, as the moral agents they are, the intertwining of all kind of pressures realizing that there exists a bioethical conflict of facts (scientific, empirical), moral values (principles) and duties (moral imperatives for some, deontic propositions or judgments for others) in relation to CTOs. This conflict, which is determined by the rules of professional authority ${ }^{13}$, inescapably obliges them from the factual normativism of principlism; and, from the complementary narrative perspective of virtue, this obligation is tied to the personal idea of practical wisdom, moral consciousness and experience, and the excellence in character of the responsible clinician who advocates the measure ${ }^{15}$. 


\section{Respect for autonomy}

Respect for autonomy is "a norm of respecting and supporting autonomous decisions", establishing the need to respect the capacity of autonomous individuals to make decisions. In other words, if "stated as a negative obligation, autonomous actions should not be subjected to controlling constraints by others" 13 .

CTO is addressed to the patient who is suffering from severe mental illness. When we speak about natural or de facto capacity of the patient with SMI, we refer to his or her aptitude to receive, understand or keep the relevant information about his or her clinical situation, with the possibility of making a choice among the possible options and their alternatives according to the personal system of values ${ }^{16}$. The critical question is how to evaluate that capacity in a clinical context. In particular, a better previous evaluation of the capacity of the patients subsidiary of CTO is needed. The first criteria for evaluating capacity were described by Roth ${ }^{17}$ as "test of capacity" until the present semi-structured interview MacArthur Competence Assessment Tool for Treatment (MacCAT-T). Other questionnaires such as Silberfeld's are also used at present.

Unlike palliative treatments applied to those persons who cannot give their consent, CTOs are given to those who refuse to consent to other necessary routine therapeutic alternatives. They are basically persons nonadherent to treatment whose natural or de facto capacity to consent is undermined due to their mental disorder, whether or not they have a legally recognized limitation or an annulment of their capacity to act. The key lies in the quality of understanding and willingness and, therefore, the consent or non consent of the person in question. When dealing with free and informed consent, a fundamental element of the autonomy principle, the effect is the transfer from doctor to patient of the responsibility for a poor therapeutic outcome $^{18}$. Here, it is necessary to consider the patient's capacity to make an autonomous decision regarding a possible intensive case management (acceptance threshold) and the capacity to understand relevant information about it (information element) ${ }^{13}$.

Mental capacity is the term used to describe the cluster of mental skills that people use in their everyday lives. An incapable patient is not considered a free person as freedom is born from autonomy and expresses the capacity for self-determination according to reason. The concept of the "sliding-scale strategy" is well known in order to determine a patient's capacity or the degree of proof needed to decide on his or her capacity. For James F. Drane ${ }^{19}$, the capacity threshold is movable and the point where placing it depends on the kind of decision to be made. The 'movable scale' has three levels: in the first, a minimal standard of capacity consisting of conscience and assent is needed; in the second one, the standard is medium and it consists of understanding and choice; and in the third level, the standard is maximum and it consists of appreciation of reality and rational decision. The decisions about giving and refusing consent to certain therapeutical interventions such as CTO are at the third level. In fact, the full knowledge or understanding of the information might be inappropriate at certain moments with some patients with SMI, despite a proper clinician-patient discussion having been maintained; similarly, the threshold for the decision-making element would also be affected. The elucidation of the latter, different for each individual patient and variable for the same patient according to his or her clinical evolution, re- 
mains today largely an exercise of phronesis by the clinician, that is, a prudent and responsible clinical judgment with limited support in capacity tests.

Parens patriae is a doctrine that grants the inherent power and authority of the State to protect persons who are legally incapable to act on their own behalf. The question of the exercise of parens patriae when faced with a patient with natural or de facto incapacity is a delicate one because the role of psychiatry could be considered as an instrument, in a sense, of social con$\mathrm{trol}^{20}$, as has happened historically with asylums ${ }^{21}$. It is the duty of the State to exercise parens patriae in a fair and equitable way in accordance with certain economically feasible and effective public health options ${ }^{8}$. However, a conflict may arise between the duty to the incapable patient with SMI and with third parties ${ }^{22}$. Paternalistic interference on the capacity of a patient's self-determination, i.e., on his or her decisions or actions, is primarily aimed at protecting his or her interests without neglecting their impact on others. The construct of autonomy is necessarily so in relation to others, i.e., it is an autonomy in contrast with other autonomies. CTOs are a "weak paternalistic" intervention system ${ }^{13}$ because they prevent an essentially involuntary action: the harm done by the non-autonomous patient to him or herself; if used principally to protect public order or a general risk to others, it would be an example of abusive political power, but if it is primarily to protect the individual it is an exercise of beneficent parens patriae authority by the State.

Hence, a CTO must necessarily result from a therapeutic decision about a patient and not from potential social alarm. Social alarm is post-crime, as is the consideration of social danger in the field of law in many Western countries. Legal security measures are to post-crime social dangerousness what the sentence by a court of law is to the punishment of a crime. Its welfare counterparts are the mental health courts, that is, the forced inpatient or outpatient treatment alternative to serving a sentence. Involuntary treatment should not be given on the basis of risk to others unless there has first been an offence. This will place the person with SMI in the same position as a non-mentally disordered person and would be consistent with 'justice' as 'fairness'. What is not acceptable, thus, are neither pre-criminal security measures nor a priori treatments as a hypothetical CTO for patients supposed to be socially dangerous.

Causing an undesired good has been called positive paternalistic interference, and avoiding an auto-inflicted harm has been termed negative interference or conservative paternalism ${ }^{13,23}$. Both are totally applicable both to patients who are de facto incapable (some SMI, although they are not incapacitated) and those declared by law (patients incapacitated by court order). In any case, the patient's welfare should take preference over the benefit to society ${ }^{24}$ and in properly understood paternalistic interference what matters is keeping an optimal balance between the clinician's beneficence and the patient's autonomy; perhaps CTO is the only chance for a patient to be able to preserve certain autonomous psychosocial functioning. There is also the risk of an excessive or extra-limited exercise of medical paternalism ${ }^{25}$, both of a positive and conservative type, which could lead to an unnecessary application of CTO. However, this possibility, which is more characteristic of hard paternalism than of soft paternalism, can also be argued demagogically as a pathetic sophism against beneficent paternalism represented by CTO, a potential example of the slippery slope fallacy. 
In summary, the patient's autonomy is a key element to be considered in CTO, but not the only one, nor necessarily the most important. The conflict of autonomy with the other prima facie principles leads to paternalistic interference. But regarding CTO this paternalism, which prevents the patient's doing harm to him or herself involuntarily, is a "soft" or false paternalism ${ }^{13,14}$, as it does not act against the patient's genuine autonomy but rather their "heteronomy" in the Kantian sense. Certain care interventions commonly regarded as paternalist such as CTO are so precisely to restore the essential or substantive autonomy of the patient (in the sense of Grace $^{26}$ ) to where it belongs and not to threaten $i^{27-29}$. Therefore, even more than soft paternalism, it is really beneficence. Consequently, the only real bioethical conflict in CTO is not between paternalism and anti-paternalism, but rather in terms of the nature, conditions and evaluation of the patient's autonomy, and the place which the respect for his or her autonomy occupies in relation to other moral principles.

\section{Non-maleficence and beneficence}

To cause harm is always wrong prima facie. Aside from the obligation of not causing harm, it is perceptive not to subject the others to the unnecessary risk of suffering it. Since Hippocrates, it has been a duty in medical ethics not to harm, to strengthen the possible benefits and to minimize risks according to the principle of primum non nocere. The Hippocratic duty of favouring is proportional, that is, it is not absolute, so if you cannot favour, at least you should do no harm $^{30}$. Regarding the application of a CTO to a given individual with SMI, his or her circumstances and the predictable consequences should be properly assessed. Possibly, its non implementation will entail the risk of causing avoidable harm to the patient, e.g., cognitive or psychosocial impairment $^{18}$. In fact, non intervention with a CTO could be considered an unsuitable form of complicity with the patient ${ }^{31}$.

The primary principle of non-maleficence is non-negotiable, it obliges (prohibits), it does not require any consent and it is an ethical imperative (in the Kantian sense) superior to that of favouring. For CTO candidate patients, not implementing it might clash with the prohibition of tolerating an avoidable harm. In the area of specific beneficence, as is the invoked for CTO candidate patients, the discretionality of general beneficence is replaced by the obligation to aid the patient ${ }^{13}$. The clinician resorts to the beneficence principle driven by the imperious need of getting the greatest good for the patient who has diminished or annulled his or her capacity. If we were referring to non-paternalistic beneficence, the free and informed consent of the patient would always be required; however, when this is not possible as it is the case with some patients with SMI, the moral imperative of promoting beneficent actions entails seeking the greatest good for the patient in all circumstances ${ }^{26}$ such as, for example, by means of CTO.

Life without some form of coercion and pressure is unlikely. There are situations which require an intervention such as a CTO to avoid certain danger, or to preserve or improve the prospects for a favourable therapeutic evolution ${ }^{32}$. The beneficent intervention, which must be obligatory provided (since it is surely the principal role of medicine and clinicians), and which could justify CTOs in itself, is to achieve the greatest welfare of the patient, to prevent his 
or her disability and to reduce avoidable suffering. Regarding the Aristotelian principle of "composite actions" in two directions, in which the direction of the intended purpose prevails ${ }^{30,33}$, it is inferred that an action or intervention such as a CTO will be morally acceptable if there is proportionality between the negative consequences (limitation of individual freedom, if only to restore it) and the positive which is directly expected. In fact, all the theoreticians of the principle of "indirect voluntary act" which constitutes the theory of the double effect (mixed actions with a possitive effect and other negative effect) consider that it is necessary to fulfil four conditions: 1 . The positive aim (benefit for the patient by applying the treatment) has to be simultaneous to the negative (court coertion); 2 . The aim directly looked for has to be the positive (improvement or cure); 3 . There is no other way to achieve the positive aim; 4 . There is proportionality between the positive effect (the treatment is an outpatient treatment and not a hospital one and it takes place in the patient's natural environment) and the tolerated negative effect (restriction of the freedom to reject the treatment).

However, it is true that in a short time we have passed from the primacy of beneficence, forgetting that there are capable patients whose opinion must be respected, to the "hyper-autonomism" or autonomist paradigm, forgetting that there are patients who are incapable of deciding whose rights must be safeguarded ${ }^{34}$. Another question is, as a reflective moral intuition in the sense of van Thiel $^{35}$, that CTO would be entirely rejectable in the form of a "silent clinical decision" 36 because of its potential for abuse; this decision is a clinical decision without involving the patient, guardian or family, based on the promotion of their welfare and utilitarian considerations such as saving time.
In addition to the condition of proportionality the principle requires, already explained as two composite actions in two directions, the condition of other less harmful alternatives is also necessary ${ }^{30}$. As will be seen when discussing the principle of justice, in the case of CTO it is necessary to properly implement the care plans or programs for SMIs, which it complements rather than replaces. One of the problems of CTOs is that mental health services focus more on the compulsory nature of the measure than on developing an acceptable form of care which would lead to an appropriate investment in resources and efforts to integrate people with SMI. This could undermine the goal of deinstitutionalisation[37], that seeks to implement integral and flexible attendance services supporting psychosocial reintegration and rehabilitation. In any case, ensuring human care and effective mental health treatment for everyone, and especially for those most in need, such as some patients with SMI, seems, as a last resort, a responsibility for the State.

\section{Justice}

Discussion on CTOs and deinstitutionalisation has occurred at the interface of ethical values and contexts in conflict ${ }^{38}$. This interface affects political, judicial, executive, police, healthcare and professional association powers. As far as legislation is concerned and with regards to CTOs, it is necessary to wonder whether we are talking about providing ill-prepared and opportunistic legal answers to the social pressure of public opinion, the media and pressure groups of civil society. In no way should this be answered, since society has the right and duty to exercise democratic construc- 
tive pressures that seem appropriate to influence the legislator, and the State has the duty to implement appropriate and coherent criminal and civil policies. Precisely because of this it does not seem that Kendra's Law (this is the way as CTO has been commonly known in New York, USA, from 1999) and Laura's Law (as CTO has been known in California, USA, from 2002), must be considered as purely opportunistic laws, a criticism which, in contrast, is often made in general terms to the Law of some Western countries such as Spain ${ }^{39}$.

Health protection is proposed as a guiding principle of social policy ${ }^{40}$. In the inevitable tension between individual care and defending the public good it is necessary, for utilitarian and pragmatic consequentialism, to maintain equity in an environment governed by efficiency ${ }^{41}$. Similarly, for principlist-deontological personalism what is fair is identified with the common good, which is not identical for all, but rather proportional ${ }^{13,42}$. The concept of health does not coincide with welfare or it is not necessarily contrary to suffering. Therefore, it rejects the medicalisation of everyday life, that is, the treatment of non-medical problems as if they were medical problems. With justice understood in this sense, for public health a fair distribution of resources and economic budgets will result in a fair, suitable and correct treatment for people with SMI with or without a CTO program. A number of these patients would have to receive a costly integrated care program for SMIs, which are generally lacking or insufficient in many other Western countries. There is, however, a clear clash of interests between the majority of patients with less severe mental disorders (such as adjustment disorder) and the minority with SMI (such as schizophrenic disorder). The first of these claim their right to be assisted by community mental health services satisfactorily in terms of time and manner, and have more weight as they are more numerous. The second group tend not to have any other defenders apart from the associations of mentally ill patients whose weight in the community is relative. The crucial, unresolved issue is, therefore, the management of psychiatric community care based on equitable distribution $^{43}$. Yet, without the proper implementation of less restrictive community treatment programs, CTOs contribute to the forced equity, we might say, of community care resources. Understood properly, it is not a question, as accepted by the fallacious argument, of replacing low-cost integrated care programs for SMIs, but to supplement them or even to force their establishment.

As we have seen, the goodness of CTO is entirely assumed also from pragmatic consequentialism and, therefore, from its extreme position, utilitarianism. In effect, its implementation and developmental costs are perfectly acceptable for any community and its overall outcome is sufficiently positive, that is, it is fair and correct. In any case, the utilitarian argument requires an ethical normativism, the utilitarianism of the rule which should promote laws to ensure a fair state of affairs. Therefore, the author's view on ethical utilitarianism supports the development of a specific law on mental health and CTOs, which is currently lacking in many Western countries.

For ontological personalist bioethics, on the other hand, everything which does not hurt the individual is licit, and everything which suppresses or hurts him or her is illicit. So, for this bioethical approach, the care of the incapable patient is an end in itself, not a means. The eminent dignity of the patient as a subject of rights requires their effective guardianship at all times. The personal dimension is a continuum which is independent from the mental state of the individual, so 
they do not lose a shred of their dignity from any disease or disorder, even if this disorder severely impinges on affectivity or judgment as happens with SMI. Consequently, a duty of respect towards the incapable patient is imposed, which has to provide the necessary action as far as society is concerned in order to safeguard the incapable patient's integrity. A CTO also appears here, then, as an obligation of bioethical justice.

Finally, to arrange hierarchically the four main principles or duties in a higher rank (non-maleficence and justice) and in a lower rank (beneficence and autonomy) from the perspective of moderate principlism ${ }^{26}$ is not important for the purpose we have seen from the bioethical foundation of CTOs, since we could not find a substantial conflict between them in connection with CTOs. We have reported frictions between the two principles of lower rank, which rather than repel each other, can merge or join regarding the important aspects. Upon the basis of the results of this work and the bioethical discussion of them, CTOs are presented, as far as the author is concerned, as a method of therapeutic intervention with a bioethical foundation resistant to criticism.

\section{Summary}

A CTO is an extraordinary means of intervention, applicable only in the absence of less restrictive care alternatives and when the patient's self-governance is severely compromised, whether or not there is courtordered incapacity to act. It has been considered that CTOs are consistent firstly with the deontologist-principlist dominant paradigm of practical reason, respecting its four general categories of basic principles. It also respects the principles of the medical ethics of virtue, subsumed in the personalism of ontological matrix, in the same way as its ethos affects the intrinsic purpose which is the dignity of the person; and with the consequentialist utilitarianism because it seeks the proportionality of the common good. When prescribing a CTO, open communication between the clinician, the patient and the family or legal guardian is crucial. This prescription must ultimately be based on a bioethical exercise of responsibility by the psychiatrist, judiciously weighing up the classic principal prima facie duties which must necessarily be translated into a real duty referring to a specific patient and context.

\section{Declaration of interest}

The author declares that there are no financial or non-financial competing interests in this work.

\section{References}

1. López M, Laviana M. Intervenciones no voluntarias en salud mental. Consideraciones sobre la propuesta de autorización judicial del tratamiento ambulatorio involuntario. Rehabil Psicosoc 2007; 4: 28-36.

2. Conde López V. El diagnóstico psiquiátrico como problema ético. In: Cervera Enguix S, Conde López V, Espino Granado A, Giner Ubago J, Leal Cercós C, Torres González F, eds. Manual del residente de psiquiatría. Vol II. Madrid: Litofinder; 1997. pp. 2349-2355.

3. Gerbasi JB, Bonnie RJ, Binder RL. Resource document on mandatory outpatient treatment. J Am Acad Psychiatry Law 2000; 28: 127-144.

4. Swartz MS, Swanson JW, Steadman HJ, Robbins PC, Monahan J. New York State assisted outpatient treatment program evaluation. Durham, NC: Duke University School of Medicine; 2009.

5. Pollack DA, McFarland BH, Mahler JM, Kovas AE. Outcomes of patients in a low-intensity, short-duration involuntary outpatient commitment program. Psychiatr Serv 2005; 56: 863-866. 
6. Swartz MS, Swanson JW. Involuntary outpatient commitment, community treatment orders, and assisted outpatient treatment: What's in the data? Can J Psychiatry 2004; 49: 585-591.

7. Erickson SK. A retrospective examination of outpatient commitment in New York. Behav Sci Law 2005; 23 : 627-645.

8. Zanni GR, Stavis PF. The effectiveness and ethical justification of psychiatric outpatient commitment. Am J Bioeth 2007; 7: 31-41.

9. Cullen-Drill M, Schilling K. The case for mandatory outpatient treatment. J Psychosoc Nurs Ment Health Serv 2008; 46: 33-41.

10. Ingram G, Muirhead D, Harvey C. Effectiveness of community treatment orders for treatment of schizophrenia with oral or depot antipsychotic medication: changes in problem behaviours and social functioning. Aust N Z J Psychiatry 2009; 43: 1077-1083.

11. O'Reilly R. Why are community treatment orders controversial? Can J Psychiatry 2004; 49: 579-584.

12. Burns T, Dawson J. Community treatment orders: how ethical without experimental evidence? Psychol Med 2009; 39: 1583-1586.

13. Beauchamp TL, Childress JF. Principles of biomedical ethics. 6th ed. New York: Oxford University Press; 2009.

14. Gracia Guillén D. Procedimientos de decisión en ética clínica. 2nd ed. Madrid: Triacastela; 2007.

15. Begley AM. Facilitating the development of moral insight in practice: teaching ethics and teaching virtue. Nurs Philos 2006;7: 257-265.

16. Generalitat de Catalunya. El ingreso no voluntario y la práctica terapéutica de medidas restrictivas en pacientes psiquiátricos y las personas demenciadas. Versión 30 de abril. Comité de Bioética de Cataluña, Departament de Salut, Generalitat de Catalunya. Disponible en: http://www.gencat.cat/salut/depsalut/ pdf/esingreso.pdf [Fecha de publicación: 05/03/2002; fecha de modificación: 09/07/2010].

17. Roth LH, Meisel A, Lidz CW. Tests of competency to consent to treatment. Am J Psychiatry 1977; 134: 279-284.

18. Dickenson D. Ethical issues in long-term psychiatric management. J Med Ethics 1997; 23:300-304.

19. Drane JF. Competency to give an informed consent. A model for making clinical assessments. JAMA 1984; 252: 925-927.

20. Szasz T. Psychiatry and the control of dangerousness: on the apotropaic function of the term "mental illness". J Med Ethics 2003; 29: 227-230.
21. Bertolín Guillén JM. Dispositivos de asistencia psiquiátrica en la España contemporánea del periodo de «entresiglos». Asclepio 1993; XLV: 189-216.

22. Szmukler G. The philosophical basis of psychiatric ethics. In: Bloch S, Chodoff P, Green SA, eds. Psychiatric ethics. 4th ed. New York: Oxford University Press; 2009. p. 363-380.

23. Callahan JC. Liberty, beneficence, and involuntary confinement. J Med Philos 1984; 9: 261-293.

24. Janssens MJ, van Rooij MF, ten Have HA, Kortmann FA, van Wijmen FC. Pressure and coercion in the care for the addicted: ethical perspectives. J Med Ethics 2004; 30: 453-458.

25. Dresser R. Involuntary confinement: legal and psychiatric perspectives. J Med Philosophy 1984; 9: 295-299.

26. Gracia Guillén D. Fundamentos de bioética. 3rd ed. Madrid: Triacastela; 2008.

27. Lawrence RE, Curlin FA. Autonomy, religion and clinical decisions: findings from a national physician survey. J Med Ethics 2009; 35: 214-218.

28. Verkerk MA. The care perspective and autonomy. Med Health Care Philos 2001; 4: 289-294.

29. Prinsen EJ, van Delden JJ. Can we justify eliminating coercive measures in psychiatry? J Med Ethics 2009; 35: 69-73.

30. Gracia Guillén D. Como arqueros al blanco. Estudios de bioética. Madrid: Triacastela; 2004.

31. Melamed Y, Doron I, Shnitt D. Guardianship of people with mental disorders. Soc Sci Med 2007; 65: 1118-1123.

32. Widdershoven G, Berghmans R. Coercion and pressure in psychiatry: lessons from Ulysses. J Med Ethics 2007; 33: 560-563.

33. Aristotle. The Nicomachean ethics. New York: Oxford University Press; 1998.

34. Chicharro Lezcano F. Tratamiento ambulatorio involuntario. Norte Salud Ment 2004; 19: 6-8.

35. van Thiel GJ, van Delden JJ. The justificatory power of moral experience. J Med Ethics 2009; 35: 234-237.

36. Whitney SN, McCullough LB. Physicians' silent decisions: because patient autonomy does not always come first. Am J Bioeth 2007; 7: 33-38.

37. WHO. Mental health legislation and human rights. Genève: WHO; 2003.

38. Peele R, Chodoff P. Involuntary hospitalization and deinstitutionalization. In: Bloch S, Green SA, eds. Psychiatric ethics. 4th ed. New York: Oxford University Press; 2009. pp. 211-228. 
39. del Riquelme Herrero P. Presión social y justicia. Legislación oportunista y juicios paralelos. In: Medina A, Moreno MJ, Lillo R, Guija JA (Eds.). Violencia, psiquiatría y ley. Madrid: Triacastela; 2009. pp. 65-96.

40. Santos Urbaneja F. Derecho y salud mental. Criterios para la formulación de un sistema eficiente. Cuad Psiquiatr Comunitar 2006; 6: 7-18.

41. Green AS. The ethics of managed mental health care. In: Bloch S, Chodoff P, Green SA (Eds.). Psychiatric ethics. 3rd ed. New York: Oxford University Press; 1999. pp. 401-420.

42. García Capilla DJ. El nacimiento de la bioética. Madrid: Biblioteca Nueva; 2007.
43. Sabin JE, Daniels N. Allocation of mental health resources. In: Bloch S, Green SA (Eds.). Psychiatric ethics. 4th ed. New York: Oxford University Press; 2009. pp. 111-125.

Author for correspondence: José Manuel Bertolín Guillén Service of Psychiatry Hospital Arnau de Vilanova San Clemente Street, 12 46015-Valencia SPAIN

Tel.: +34627452615

Fax: +34963868726

Email: jmbertolin@comv.es 